\title{
Evaluation of two microscale flow models through two wind climate generalization procedures using observations from seven masts at a complex site in Brazil
}

\author{
Gomes da Silva, Adaiana F.; Peña, Alfredo; Hahmann, Andrea N.; Luiz Zaparoli, Edson
}

Published in:

Journal of Renewable and Sustainable Energy

Link to article, DOI:

$10.1063 / 1.5027692$

Publication date:

2018

Document Version

Publisher's PDF, also known as Version of record

Link back to DTU Orbit

Citation (APA):

Gomes da Silva, A. F., Peña, A., Hahmann, A. N., \& Luiz Zaparoli, E. (2018). Evaluation of two microscale flow models through two wind climate generalization procedures using observations from seven masts at a complex site in Brazil. Journal of Renewable and Sustainable Energy, 10(5), [053306]. https://doi.org/10.1063/1.5027692

\section{General rights}

Copyright and moral rights for the publications made accessible in the public portal are retained by the authors and/or other copyright owners and it is a condition of accessing publications that users recognise and abide by the legal requirements associated with these rights.

- Users may download and print one copy of any publication from the public portal for the purpose of private study or research.

- You may not further distribute the material or use it for any profit-making activity or commercial gain

- You may freely distribute the URL identifying the publication in the public portal 


\section{Evaluation of two microscale flow models through two wind climate generalization procedures using observations from seven masts at a complex site in Brazil}

Adaiana F. Gomes da Silva, Alfredo Peña, Andrea N. Hahmann, and Edson Luiz Zaparoli

Citation: Journal of Renewable and Sustainable Energy 10, 053306 (2018); doi: 10.1063/1.5027692

View online: https://doi.org/10.1063/1.5027692

View Table of Contents: http://aip.scitation.org/toc/rse/10/5

Published by the American Institute of Physics

\section{Articles you may be interested in}

Active disturbance rejection based MPPT control for wind energy conversion system under uncertain wind velocity changes

Journal of Renewable and Sustainable Energy 10, 053307 (2018); 10.1063/1.5037916

\section{Don't let your writing keep you from getting published!}




\title{
Evaluation of two microscale flow models through two wind climate generalization procedures using observations from seven masts at a complex site in Brazil
}

\author{
Adaiana F. Gomes da Silva, ${ }^{1, a)}$ Alfredo Peña, ${ }^{2}$ Andrea N. Hahmann, ${ }^{2}$ \\ and Edson Luiz Zaparoli ${ }^{1}$ \\ ${ }^{1}$ Division of Mechanical Engineering, Technological Institute of Aeronautics (ITA), \\ São José dos Campos, Brazil \\ ${ }^{2}$ DTU Wind Energy, Technical University of Denmark, Roskilde, Denmark
}

(Received 5 March 2018; accepted 11 September 2018; published online 28 September 2018)

\begin{abstract}
Two microscale flow models, a linear and a computational fluid dynamics model solving the Reynolds-averaged Navier-Stokes equations, are evaluated using observations from seven masts at Araripe wind farms, located on a complex terrain area in the northeast region of Brazil. The evaluation is performed by generalizing the wind climate from the masts. By doing so, the effects induced by the local topography on the surface wind are removed, resulting in the background wind field, which is the ideal undisturbed flow over flat terrain with uniform roughness. Here this is performed in two ways: using the time series of 10-min mean winds and using wind speed distributions. Non-negligible differences are found on the generalized winds when comparing the results from the two methods. For both generalization methods, the results obtained using the more complex flow model show significant improvements when compared to those obtained from the linear model at few locations and for particular inflow directions only. Published by AIP Publishing. https://doi.org/10.1063/1.5027692
\end{abstract}

\section{INTRODUCTION}

Energy consumption grows yearly, and the use of wind energy has increased enormously worldwide in recent years. As the wind speed varies spatially and seasonally, wind farms are ideally installed at high wind-potential sites with strong and persistent winds. As wind farms must be installed at sites with good wind resources to be profitable, it is imperative to perform energy yield assessments with low uncertainties (Banshwar et al., 2017; Murthy and Rahi, 2017). One way to achieve this is to reduce the uncertainty of wind-flow microscale models. These models provide the means to estimate the behavior of the wind in the presence of local features.

The motions in the atmosphere have different time and spatial scales ranging from those of the molecules to those of weather systems. Models are hence developed in distinct ways to represent the atmosphere on their different scales (Petersen et al., 1998a). This has been facilitated due to major progress in numerical modelling development and in computer power. Currently, in the wind industry, different numerical approaches are employed: linearized, mass-consistent, and computational fluid dynamics (CFD) models on the microscale and numerical weather prediction (NWP) models on the mesoscale. CFD models use different approximations, and the approaches using Reynolds-averaged Navier-Stokes (RANS) and large eddy simulation (LES) are nowadays the most common. The main difference between the last two is the way in which turbulence is modelled.

Microscale models are dedicated to those atmospheric processes occurring at the smaller scales of time and space, approximately smaller than $1 \mathrm{~km}$ and 1 day (Foken, 2008). In wind energy, microscale models are used to estimate wind resources (Ayotte, 2008; Rasouli and Hangan, 2013; Albani and Ibrahim, 2014; Blocken et al., 2015) considering the influence of the local terrain on the

${ }^{a)}$ Electronic mail: adaiana1@yahoo.com.br 
flow and taking into account the interaction with the large scale atmospheric motion generally through boundary conditions at the domain borders. Measurements taken inside or near the considered region and that represent a sample of the local climatology are extrapolated horizontally and vertically to adjust the simulated wind field to the observations (Ayotte, 2008).

As discussed in Petersen et al. (1998b), Yamada and Koike (2011), Gasset et al. (2012), Blocken et al. (2015), and Castellani et al. (2015), within the surface layer, which normally does not exceed $200 \mathrm{~m}$ above the ground level, most of the microscale models assume steady-state flow and neutral stratification of the atmosphere, which is reasonable under strong wind conditions. However, such circumstances are hypothetical and seldom found in the nature. Thermal stratification, e.g., can have a large influence on the wind response to the terrain (Jothiprakasan, 2014). Improving tools for microscale modelling is therefore part of the daily goals of wind researchers.

Due to the existence of different atmospheric scales, there is the need to couple models resolving particular features of the atmosphere. Storm et al., (2008), Schlünzen et al. (2011), and Basu (2013) explored different ways of performing model coupling. In meso-microscale coupling procedures (Zajaczkowski et al., 2011; Gasset et al., 2012; Bilal et al., 2016), the local effects are simulated taking into account the effect of the large scale transient meteorological phenomena. One method to compare coupling techniques is through wind climate generalization (Badger et al., 2014; Hahmann et al., 2016), sometimes also referred to as the wind atlas method, first proposed by Troen and Petersen (1989).

The wind climate generalization is based on removing the effects induced by the local topography (orography, roughness, and obstacles) on the flow to estimate the undisturbed atmospheric flow. The generalized wind is therefore the background wind field, i.e., the ideal undisturbed flow over a perfectly flat terrain with a uniform roughness length, at any given value.

In the present study, the wind generalization method is applied to a long time series of wind measurements from seven meteorological masts installed in a complex site located in the Northeast region of Brazil (Araripe plateau). The Brazilian northeast has a very high wind potential due to the prevalence of trade winds and concentrates many wind farms (Amarante et al., 2001; de Jong et al., 2017). Atmospheric flow over this region is particularly complex due to the presence of an escarpment close to the measurement sites and due to uneven surface heating. The surface temperature at the plateau (high land) is often lower than that at the low land. The trade winds and the effect of thermal buoyancy increase the wind resources when approaching the plateau escarpment. A similar generalization procedure was used in relevant previous works for mesoscale modeled winds (Badger et al., 2014; Lennard et al., 2015; Hahmann et al., 2016).

For the generalization process, we simulate the effect of the microscale topography features on the wind using both linear and CFD modelling approaches which are available in the Wind Atlas Analysis and Application Program (WAsP) program. Specifically, the wind climate generalization method is evaluated under different statistical treatments of wind data. The idea is to apply the procedure in two different ways: (1) over the time series of 10-min mean winds and (2) over the sector-wise wind speed distributions. The latter is performed inside WAsP itself. The impact of the results of this work is also high because we deal with large amounts of wind data and due to the exemplary equatorial complex area.

This paper is organized as follows: in Sec. II, the two wind flow models used in this work are described, as well as the two wind climate generalization methods. In Sec. III, the features of the study area and the observed dataset collected from the seven met masts are presented, including the data quality inspection. The results from the generalizations are discussed in Sec. IV. Analyses are carried out on a sector-wise basis and also on the omni-directional wind speed distribution for different heights above the ground level. Vertical wind profiles are also part of our analysis. The main outcomes of this work are given in the conclusions.

\section{NUMERICAL METHODS}

\section{A. Description of the wind flow models}

The numerical approaches employed in linear and in CFD RANS models are discussed in this section. In general, for neutrally stratified flows, linear models are deemed to estimate wind 
resources with smaller errors for terrains of gentle slopes, when compared to the errors that can be found over complex terrain (Bowen and Mortensen, 2004; Cabezón et al., 2006; Palma et al., 2008), which are mainly caused by the linearization of the governing equations. This limits the use of this approach nowadays since there are an increasing number of wind farms in complex terrains. On the other hand, when compared to linear models, CFD models are generally thought to be better suited for complex terrain applications (Bechmann et al., 2011; Rasouli and Hangan, 2013; Blocken et al., 2015) because they include non-linear effects, e.g., flow separation, and non-linear terms, e.g., advection, coupling between shear and stress, and stress and pressure perturbation (Mortensen et al., 2013).

Linear models were originally developed in the 1980s and 1990s based on the theory of Jackson and Hunt (1975). The models go beyond mass conservation to include momentum conservation by solving a linearized form of the Navier-Stokes equations. The fundamental idea of these models is that the local perturbations caused by the terrain's microscale features modify the winds near the surface. In the model by Jackson and Hunt (1975), the flow is divided into an inner layer where the perturbation is dynamically significant and turbulence prevails and an inviscid outer layer where the perturbation essentially vanishes. The equations of motion are linearized by estimating the velocity as the sum of the upstream velocity and a small perturbation. Turbulence closure in the inner layer is achieved by a simple mixing-length model (Brower, 2012; Zhang, 2015).

The CFD model consists of a numerical method for solving non-linear partial differential equations (PDEs) that represent a physical flow field. Through a discretization scheme, the continuum solution domain is transformed into a discrete problem with a finite number of nodal points over a 3-dimensional grid. The PDEs are then integrated over the computational grid and transformed into a system of algebraic equations that is solved iteratively until a converged solution is obtained according to pre-established error criteria (Versteeg and Malalasekera, 1995). The wind field is simulated considering only the local terrain features and standard inlet boundary conditions. To simulate turbulent flows, CFD tools can use a RANS approach solving momentum, mass conservation, energy, and turbulence model equations (for example, the $k-\tilde{a}$ model) to obtain average flow field characteristics (velocity, pressure, and temperature).

The linear WAsP IBZ model comprises an orographic flow model, the Bessel Expansion on a Zooming Grid (BZ) model (Troen, 1990), and a roughness change model, the internal boundary layer (IBL) model (Sempreviva et al., 1990), which are combined to calculate the topographical effects on the wind flow. The BZ model is a linearized spectral flow model for a neutral boundary layer. It computes the coefficients of a Fourier-Bessel expansion of the potential flow perturbation on a polar computational grid, with radial spacing concentrated near the centre and increasing with the distance. The model gradually smoothens the terrain around the predicting site along a $10-100 \mathrm{~km}$ diameter circle. The meshing is performed individually for each site (Troen and Petersen, 1989; Walmsley et al., 1990).

The WAsP CFD model employs the EllipSys flow solver (Michelsen, 1992; Sørensen, 1995) that discretizes the RANS equations in a finite-volume scheme. The numerical solution is stopped when all variable residuals are lower than $5.10^{-5}$. Simulations are repeated for 36 wind directions. The turbulence is modelled using a two equation $k-\epsilon$ (turbulent energy and dissipation) closure. The closure constants implemented in WAsP CFD are those shown in Table II of Bechmann (2016). The results are the flow perturbations per upstream wind direction with a 20$\mathrm{m}$ horizontal resolution, at several levels above the ground. As in the linear model, the flow perturbations are relative to a specified far upstream inflow logarithmic profile, being a function of the topography only. A zooming polar grid along a $\approx 30-\mathrm{km}$ diameter circle is applied with terrain-following coordinates (Bechmann, 2013; Troen et al., 2014; Cavar et al., 2016). CFD calculations and grid generation are fully automatic in WAsP CFD (Bechmann, 2013, 2016, 2017).

In both the WAsP IBZ and CFD approaches, the atmosphere is assumed to be neutrally stratified, in steady-state and incompressible. The treatment of stratification is performed by deviating the neutral logarithmic wind profile in the background, which is independent of the IBZ or CFD model results, to reflect the climatology of the stability of the site via heat fluxes. 
In WAsP, Coriolis effects are neglected in both the IBZ and CFD models, and so, the flow speed-ups are functions of topography only. This assumption is quite reasonable for the area of study considering its proximity to the equator. The deflection in the wind direction caused by the orography is provided in WAsP, as well as the logarithmically weighted upstream roughness from a given direction, which is the reference roughness.

In the present work, terrain input comes from the 90-m horizontal resolution elevation data derived from the Shuttle Radar Topography Mission (SRTM) from the United States Geological Survey (USGS) (https://lta.cr.usgs.gov/SRTM) and 30-m horizontal resolution land cover data from the Global Land Cover (GLC30) databases (http://www.globallandcover.com).

\section{B. The wind generalization method}

In this study, both the generalizations and the self-predictions are performed in two ways:

- Time-series analysis (TSA): The generalization procedure is applied for every single realization (a 10-min mean) over the time series;

- Frequency-distribution analysis (FDA): The generalization procedure is applied over the frequency-distribution of 10-min means, performed directly by WAsP.

The generalization method starts by computing the geostrophic wind from the surface wind. Since the surface wind is affected by the local topography features, a microscale model is used to extract the effect of the topography on this surface wind. The generalized wind is then the wind estimated over flat terrain at a standard height and a standard roughness length from the computed geostrophic wind. In this study, the winds are always generalized to a standard roughness length of $0.03 \mathrm{~m}$.

The effects of local topography features are given in WAsP as 'speed-ups'. They are provided as the percentage of increase or decrease in the actual observed wind speed $(u)$

$$
\hat{u}=\frac{u}{\delta S_{\text {oro }} \delta S_{\text {rou }}},
$$

where $\hat{u}$ is the intermediate wind speed adjusted with the orography and roughness speed-up factors $\delta S_{\text {oro }}$ and $\delta S_{\text {rou }}$. Further, the intermediate wind direction $\hat{\alpha}$ is estimated as

$$
\hat{\alpha}=\alpha-\delta \alpha,
$$

where $\delta \alpha$ is the effect of the orography on the wind direction $\alpha$.

From the logarithmic wind profile, the friction velocity $u_{*}$ is computed [Eq. (3)] and used to estimate the geostrophic wind $G$ via the geostropic drag law [Eq. (4)]

$$
\begin{gathered}
u_{*}=\frac{\kappa \hat{u}}{\ln \left(\frac{z_{\text {obs }}}{z_{0 \text { ref }}}\right)}, \\
G=\frac{u_{*}}{\kappa} \sqrt{\left[\ln \left(\frac{u_{*}}{|f| z_{\text {oref }}}\right)-A\right]^{2}+B^{2}},
\end{gathered}
$$

where $\kappa$ is the von Karman constant $(0.4), z_{o b s}$ is the height of the observation above the ground, $z_{0 r e f}$ is the reference roughness length, $f$ is the Coriolis parameter (considering a minimum latitude of $10^{\circ}$ ), and $A$ and $B$ are the resistance-law constants with the values of 1.8 and -4.5 , respectively (Troen and Petersen, 1989; Badger et al., 2014). Then, Eq. (4) is used iteratively to estimate a new friction velocity $u_{*_{G}}$ but replacing $z_{0 \text { ref }}$ by $z_{0 s t d}$, i.e., the standard roughness length $(0.03 \mathrm{~m})$. A residual error criterion of $0.1 \%$ is used to stop the iterations.

The generalized wind $u_{g e n}$ at the standard height $z_{s t d}$ can be estimated with the logarithmic wind profile using $z_{0 s t d}$ and $u_{*_{G}}$ 


$$
u_{\text {gen }}=\frac{u_{*_{G}}}{\kappa} \ln \left(\frac{z_{s t d}}{z_{0 s t d}}\right)
$$

Finally, it is necessary to consider the wind rotation to get the generalized wind direction $\alpha_{g e n}$

$$
\alpha_{g e n}=\hat{\alpha}+\arcsin \left(\frac{B u_{*}}{\kappa G}\right)-\arcsin \left(\frac{B u_{*_{G}}}{\kappa G}\right) .
$$

The second and third terms on the right side represent the geostrophic turning. It is caused by the different friction velocities $u_{*}$ and $u_{*_{G}}$, deviating the pressure gradient force from its natural direction perpendicular to the Coriolis force (Troen and Petersen, 1989; Badger et al., 2014).

The calculations to obtain self-predictions, i.e., predictions at the same positions of the met masts, are basically the same, but the reference roughness is kept in the up and down process (Mortensen et al., 2013). Here, the data from $100 \mathrm{~m}$ are used as the reference to self-predict the winds at 80 and $120 \mathrm{~m}$.

For the time-series analysis, we perform this procedure for each 10-min mean, and then, we derive sector-wise statistics including the mean power density $(P D)$

$$
P D=\frac{1}{2} \rho \overline{u^{3}}
$$

where $\rho$ is the air density, here assumed to be $1.225 \mathrm{~kg} / \mathrm{m}^{3}$, and $\overline{u^{3}}$ is the mean value of the third power of the wind speed.

\section{SITE AND MEASUREMENTS}

The meteorological (met) masts used in this study were installed in the Northeast region of Brazil, at the border between the states of Pernambuco and Piauí (see Fig. 1). The area, called Chapada do Araripe, is a plateau with very steep slopes, up to $40 \mathrm{deg}$, and its flat top reaches almost $400 \mathrm{~m}$ above the lower base of the terrain around it, as seen in Fig. 1-middle, which shows the map of the area and its height above the sea level. In this area, orographic effects dominate over those caused by roughness length variations. The figure also shows the positions of seven met masts. The two black rectangles represent the orography and the roughness computational domains used in WAsP. The former extends along $25.5 \mathrm{~km} \times 30 \mathrm{~km}$, while the latter is slightly larger $(\approx 29.5 \mathrm{~km} \times 34 \mathrm{~km})$. Both domains are centered at $7.64^{\circ} \mathrm{S}$ and $40.65^{\circ} \mathrm{W}$.

Time series of 10-min mean wind speed and direction for more than two years of observations are used in this study. Thies Clima cup anemometers and wind vanes were placed at three heights in the seven triangular lattice met masts shown in Fig. 1. The instruments are located on 2.0-2.4 $\mathrm{m}$ long booms protruding from the sides of the mast and face approximately the directions $28^{\circ}, 208^{\circ}$, or both; the choice of direction depends on whether or not the particular height and mast have a second and redundant cup anemometer at the same height. These boom orientations are nearly perpendicular to the predominant wind direction to avoid flow distortion as much as possible. The details of the available data are given in Table I. The shortest (largest) distance between two masts is $1.9(10.5) \mathrm{km}$.

\section{A. Wind data treatment}

The full dataset is subjected to quality inspection. This concerns filtering out repeated and incorrect values (e.g., undefined, negative, or unrealistic samples with mean wind speeds above $99 \mathrm{~m} / \mathrm{s}$ ). This procedure filters less than $1 \%$ of the total of available measurements.

After the data quality check, only concurrent values among all masts and heights are kept. $\approx 8600010$-min samples, i.e., $85.2 \%$ of the data, are left for the analysis (for each mast and height), starting on 1 April 2014 and ending on 1 March 2016. 


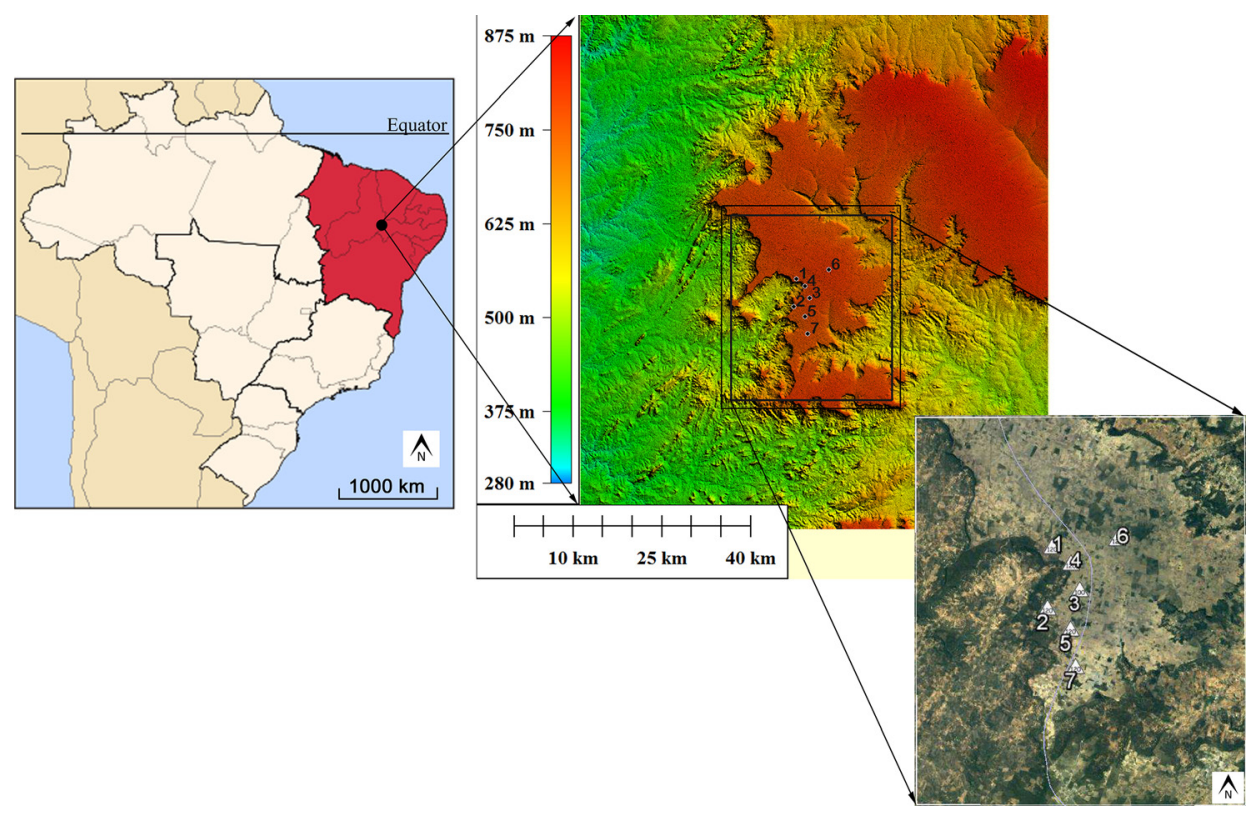

FIG. 1. The location of the area of study on a map of Brazil (left) and the terrain elevation map of the Araripe plateau and simulation domains (middle) with the seven met masts (right).

During the considered period, $80 \%$ of all data samples come from the sectors centered at $90^{\circ}$ and $120^{\circ}\left(30^{\circ}\right.$ size $)$ as shown in the wind rose in Fig. 2. Such predominance is due to the influence of the trade winds, characterized as strong and persistent winds coming from southeast.

In addition, we also perform checks on the turning of the wind by comparing direction observations at different heights (see Fig. 3). All masts show similar results. The variation of the wind direction with the height is small and allows us to use the observed wind directions from $100 \mathrm{~m}$ for pairing with the observed wind speeds at $80 \mathrm{~m}$ since there were no vanes available at this height.

\section{RESULTS}

\section{A. Generalization}

For simplicity, the comparison of generalized winds is shown only at 80 and $100 \mathrm{~m}$. Nonetheless, values at $120 \mathrm{~m}$ are later considered for the self-predictions.

The comparison between the wind speeds generalized using the TSA and FDA methods is shown in Fig. 4. All masts and directions are shown. Although the plot shows results for IBZ

TABLE I. Available mast data. $\mathrm{S}=$ wind speed measurements and $\mathrm{D}=$ wind direction measurements.

\begin{tabular}{lccccc}
\hline \hline & \multicolumn{3}{c}{ Wind measurements levels } \\
\cline { 2 - 5 } Mast identity (ID) & $80 \mathrm{~m}$ & $100 \mathrm{~m}^{\mathrm{a}}$ & $100 \mathrm{~m}^{\mathrm{b}}$ & $120 \mathrm{~m}^{\mathrm{a}}$ & $120 \mathrm{~m}^{\mathrm{b}}$ \\
\hline M1 & $\mathrm{S}$ & $\mathrm{S}, \mathrm{D}$ & $\mathrm{S}, \mathrm{D}$ & $\mathrm{S}$ \\
M2 & $\mathrm{S}$ & S,D & & $\mathrm{S}, \mathrm{D}$ & $\mathrm{S}$ \\
M3 & S,D & S,D & $\mathrm{S}$ & $\mathrm{S}, \mathrm{D}$ & $\mathrm{S}$ \\
M4 & $\mathrm{S}$ & S,D & & $\mathrm{S}, \mathrm{D}$ & $\mathrm{S}$ \\
M5 & $\mathrm{S}$ & S,D & & S,D & \\
M6 & $\mathrm{S}$ & S,D & S,D & \\
M7 & $\mathrm{S}$ & S,D & & & \\
\hline \hline
\end{tabular}

${ }^{\mathrm{a}}$ and ${ }^{\mathrm{b}}$ indicate the instruments at the two ends of the booms. 


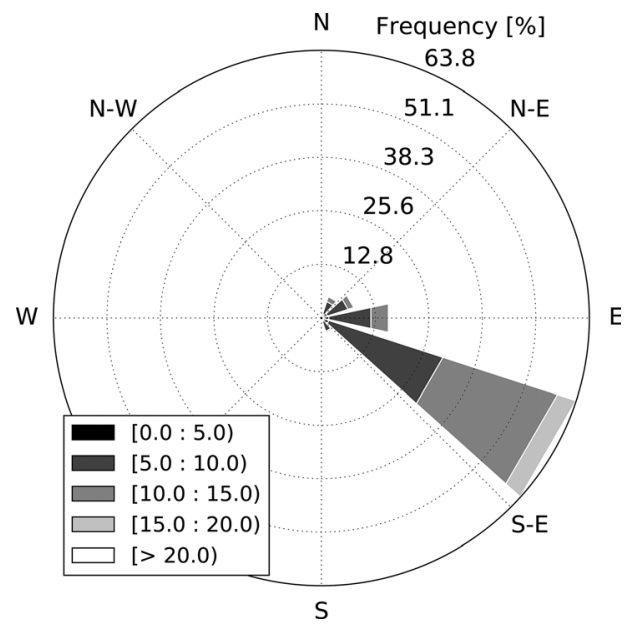

FIG. 2. Wind rose observed over the Araripe region from April 2014 to March 2016 for all instruments together.
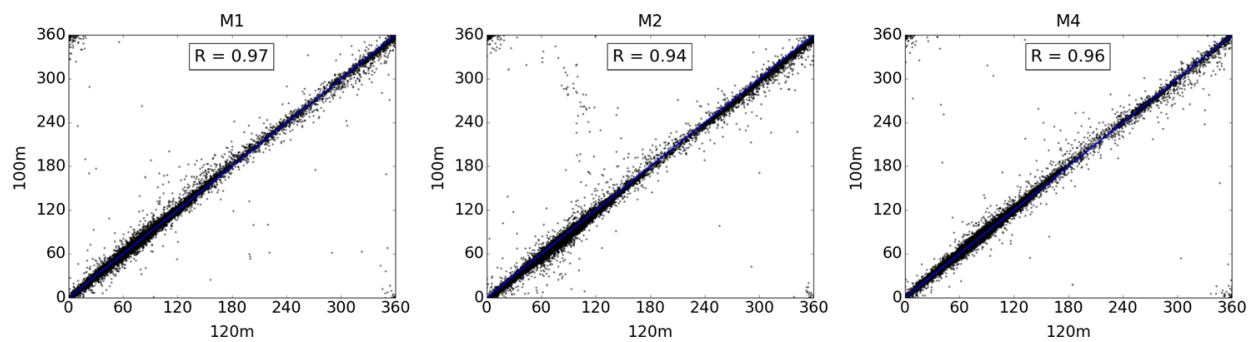

FIG. 3. Comparison of wind directions at two heights for three different masts. The linear correlation coefficient $\mathrm{R}$ is also given.

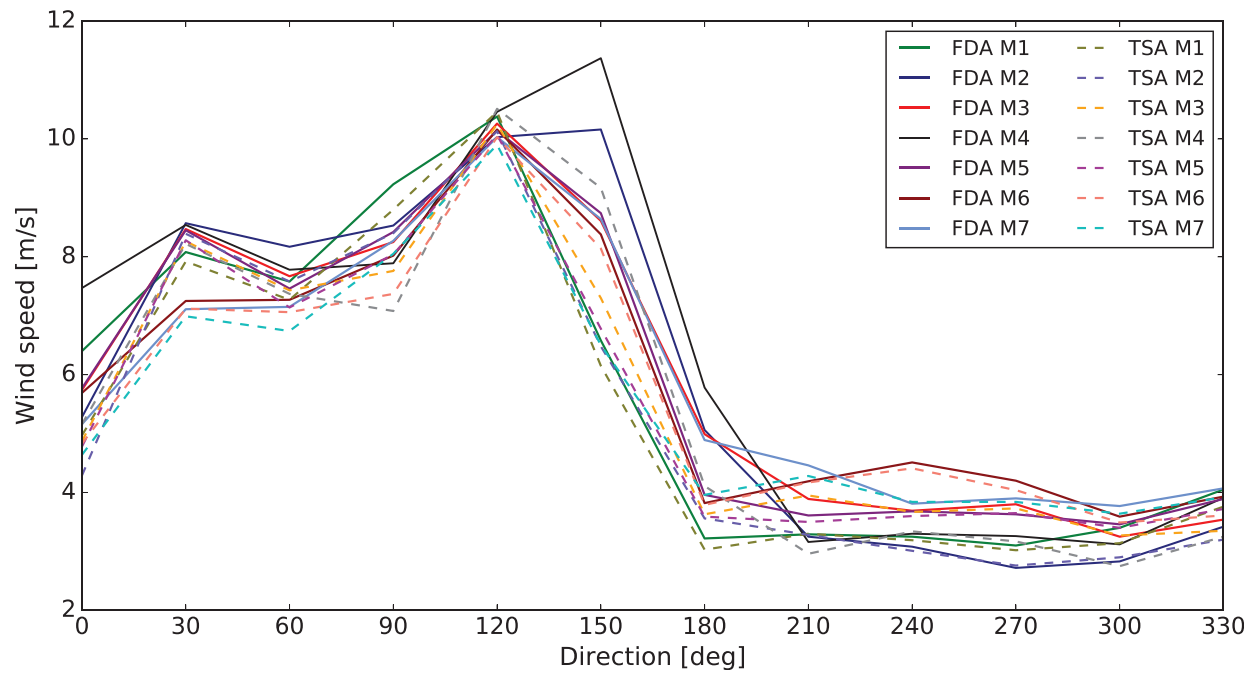

FIG. 4. Comparison between the generalized wind speeds at $100 \mathrm{~m}$ performed by FDA (solid lines) and by TSA (dashed lines) using the IBZ model. 
at $100 \mathrm{~m}$ only, the qualitative behavior of the results is the same for all the heights, differing only in magnitude. The results are also similar when comparing the two approaches, IBZ and CFD. It is important to note that under the ideal scenario of perfect flow models and generalization methodologies and the same regional wind climate at all sites, the generalized winds should be the same at all sites.

The wind speeds generalized by FDA tend to be higher than those generalized by TSA. The generalizations performed by FDA for masts 2 and 4 show higher wind speeds at $150^{\circ}$ than at $120^{\circ}$, which is the opposite trend for the other masts. At $120^{\circ}$, all the results converge to values around $10 \mathrm{~m} / \mathrm{s}$. Further, under the less predominant sectors $\left(180^{\circ}-330^{\circ}\right)$, the wind speed is low.

Figures 5 and 6 illustrate cross-comparisons of wind speed and power density at $80 \mathrm{~m}$ between various sets of two masts for three sectors. In total, the 21 possible mast pairs are considered.

Figure 5 shows comparisons between the IBZ and CFD approaches when using the TSA method. Due to the unfeasibility of presenting all sets of figures, i.e., for each wind direction sector, only three are here illustrated: $30^{\circ}, 120^{\circ}$, and $150^{\circ}$ are chosen as representative of the different results. For $30^{\circ}$ and $120^{\circ}$, the generalization reduces the differences in wind speed when compared to the differences in the observations. The opposite behavior is observed for $150^{\circ}$. The highest differences at $150^{\circ}$ are seen when using the IBZ model. At $120^{\circ}$, the CFD model shows slightly higher differences than those using the IBZ model, and at $30^{\circ}$, the results are quite similar for both approaches.
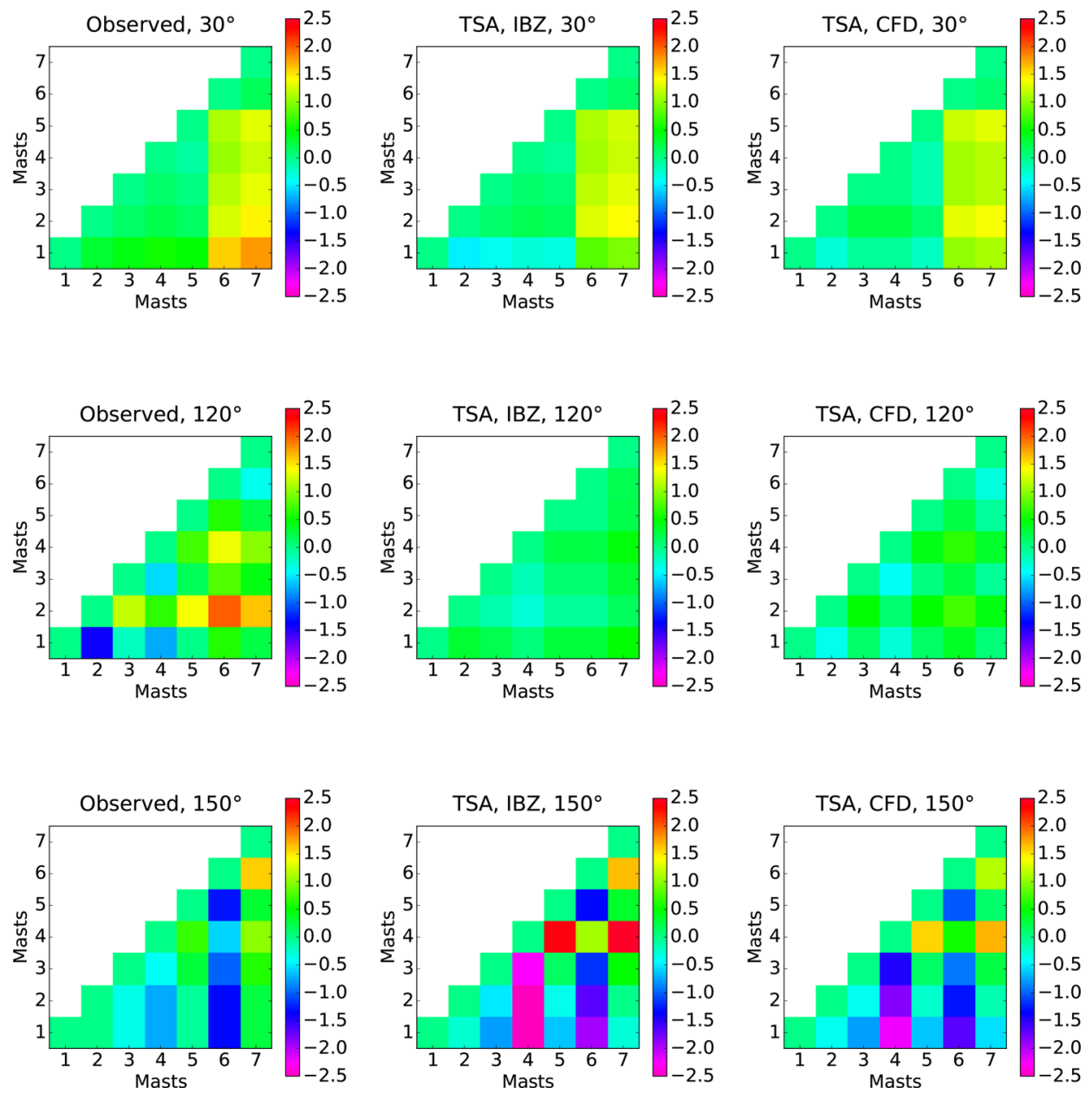

FIG. 5. Cross-comparison of wind speeds at $80 \mathrm{~m}$ between masts for raw measurements (left) and generalized winds with TSA using the IBZ model (middle) and the CFD model (right). $30^{\circ}, 120^{\circ}$, and $150^{\circ}$ are shown, respectively, on the top, middle, and bottom frames. Colors represent the differences in $\mathrm{m} / \mathrm{s}$. 

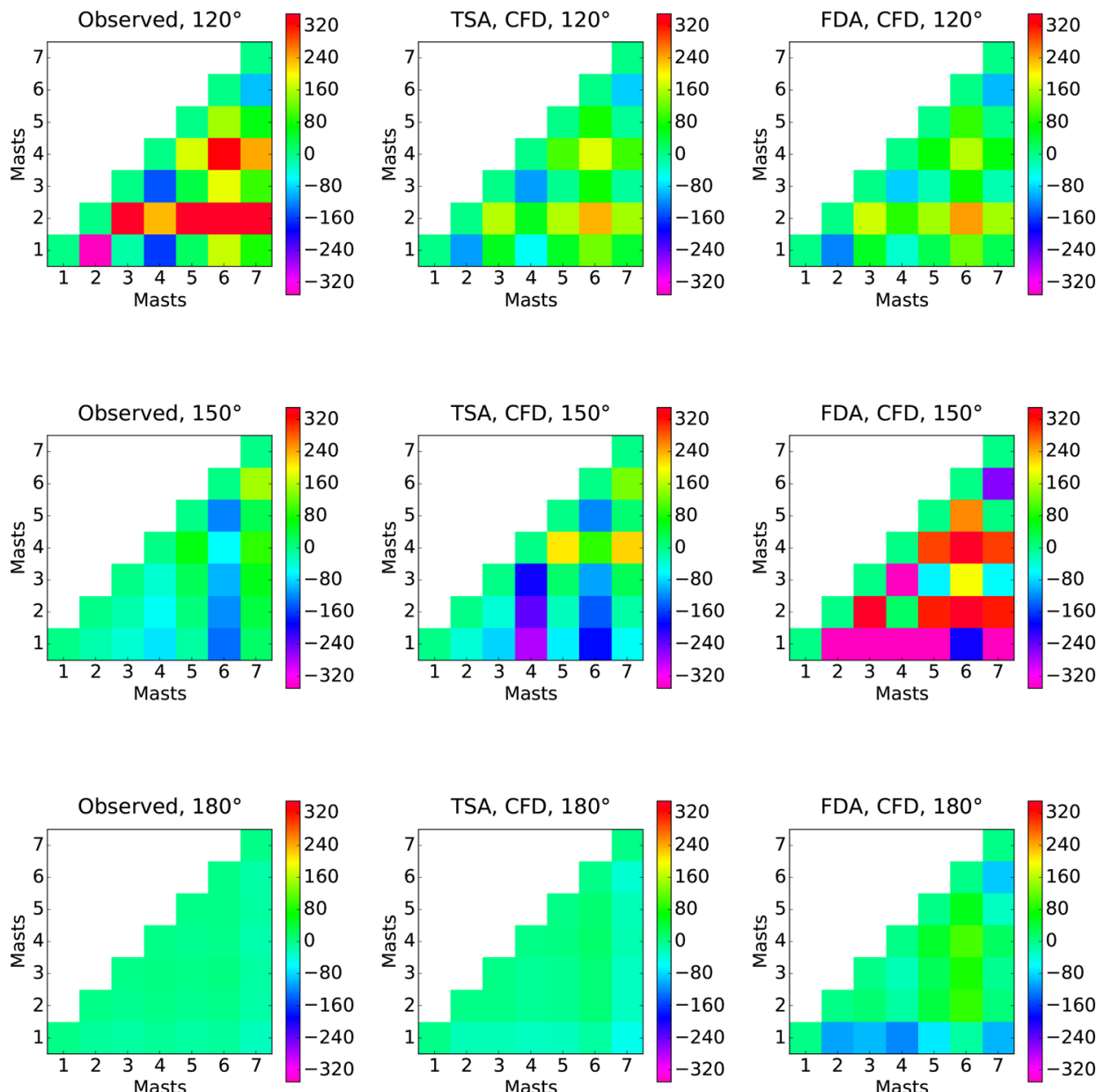

FIG. 6. Cross-comparison of power density at $80 \mathrm{~m}$ between masts for raw measurements (left) and generalized winds with TSA (middle) and with FDA (right), both using CFD parameters. $120^{\circ}, 150^{\circ}$, and $180^{\circ}$ are shown on top, middle, and bottom frames. Colors represent the differences in $\mathrm{W} / \mathrm{m}^{2}$.

In Fig. 6, the comparison is between the methods TSA and FDA in terms of power density, exemplified by the sectors $120^{\circ}, 150^{\circ}$, and $180^{\circ}$. In this case, generalization reduces the differences for $120^{\circ}$, as in the previous analysis, with nearly equal results for the two generalization methods. For $150^{\circ}$, the generalization by FDA shows a large spread in the power density over the region when compared to the observations. The differences in power density also increase after the generalization by TSA but less than by FDA. For $180^{\circ}$, the differences in FDA results are larger than those in TSA results, as for $150^{\circ}$, but in a very lesser degree. In most cases, the pairs with the largest differences involve the masts close to the escarpment (M2 and M4).

Figures 7 and 8 present general sector-wise statistics of all masts (mean and standard deviation) at $100 \mathrm{~m}$. Besides presenting the highest mean observed wind speeds, the most frequent sectors (around $90^{\circ}-120^{\circ}$ ) also show the highest observed standard deviations. From $30^{\circ}$ to $120^{\circ}$, the observed standard deviations are higher than those after generalization, which is the expected behavior from the generalization process. Regarding generalizations, standard deviations estimated after using the CFD results are slightly higher than those using the IBZ results for sectors $60^{\circ}, 90^{\circ}$, and $120^{\circ}$. The standard deviations for results obtained using FDA are generally higher than those using TSA, except for the sectors $90^{\circ}, 120^{\circ}$, and $330^{\circ}$ when considering the wind speeds and $90^{\circ}$ (IBZ only) when considering the power density. The mean wind speed after generalization is very close for both methods for $120^{\circ}$ and some other low frequent directions and is most different for $0^{\circ}, 150^{\circ}$, and $180^{\circ}$. Sector $150^{\circ}$ is perhaps the most critical in terms of standard deviation for FDA generalizations ( $1.39 \mathrm{~m} / \mathrm{s}$, IBZ, and $1.24 \mathrm{~m} / \mathrm{s}, \mathrm{CFD})$. 

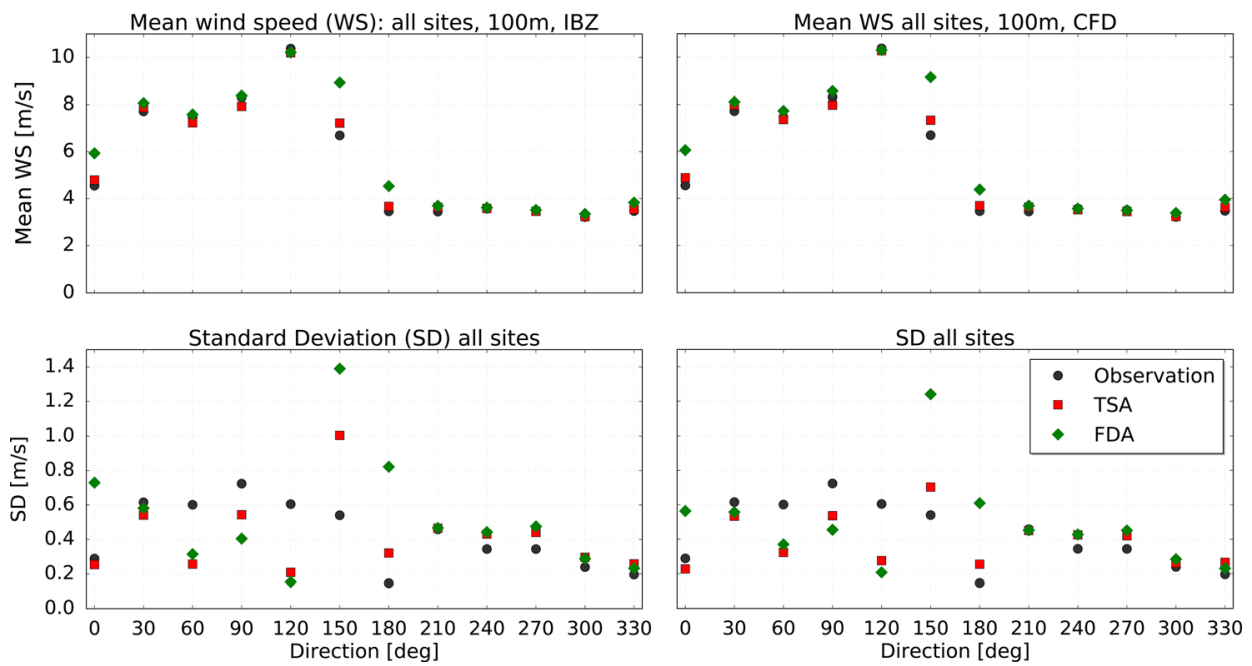

FIG. 7. Comparisons between observations and both generalization methods, for IBZ (left) and CFD (right). The top (bottom) figures are for mean (standard deviations) wind speeds among all sites.
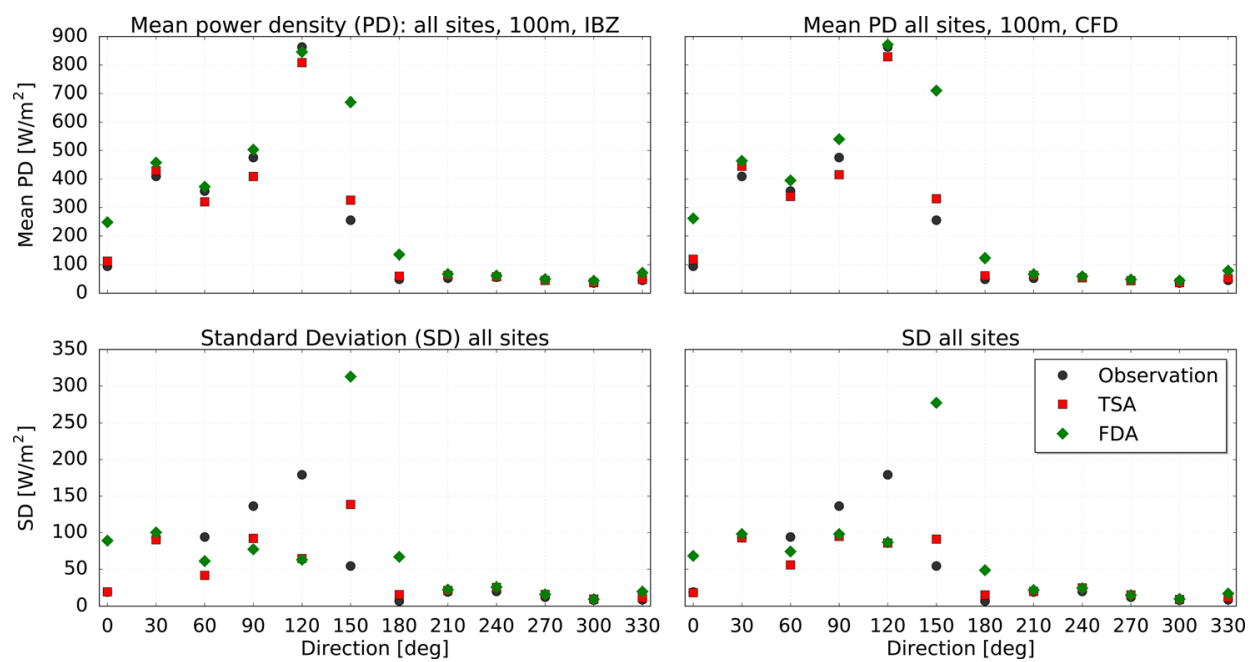

FIG. 8. The same as Fig. 7 but for power density.

Table II shows the wind speed generalized using the IBZ model at each mast against the mean among all masts for sector $150^{\circ}$. The results for M4 are the farthest from the average, followed by M1. The same behavior is observed with CFD (not shown), but the differences among the masts are smaller. Figure 9 shows the observed and the generalized wind roses at $80 \mathrm{~m}$. There is a significant increase in the frequency of samples in sector $150^{\circ}$ for $\mathrm{M} 4$ after generalization, which does not occur for any other mast. M2 (the other mast close to the escarpment)

TABLE II. Generalized wind speed $[\mathrm{m} / \mathrm{s}]$ at each mast and on average for the $150^{\circ}$ sector using IBZ model results.

\begin{tabular}{|c|c|c|c|c|c|c|c|c|c|}
\hline & Height & M1 & M2 & M3 & M4 & M5 & M6 & M7 & Mean all masts \\
\hline \multirow[t]{2}{*}{ TSA } & $80 \mathrm{~m}$ & 5.96 & 6.23 & 6.73 & 8.99 & 6.59 & 7.90 & 6.24 & 6.95 \\
\hline & $100 \mathrm{~m}$ & 6.15 & 6.48 & 7.30 & 9.17 & 6.78 & 8.14 & 6.50 & 7.22 \\
\hline \multirow[t]{2}{*}{ FDA } & $80 \mathrm{~m}$ & 6.40 & 9.80 & 8.26 & 11.14 & 8.48 & 8.05 & 8.38 & 8.64 \\
\hline & $100 \mathrm{~m}$ & 6.58 & 10.16 & 8.61 & 11.37 & 8.74 & 8.38 & 8.64 & 8.93 \\
\hline
\end{tabular}



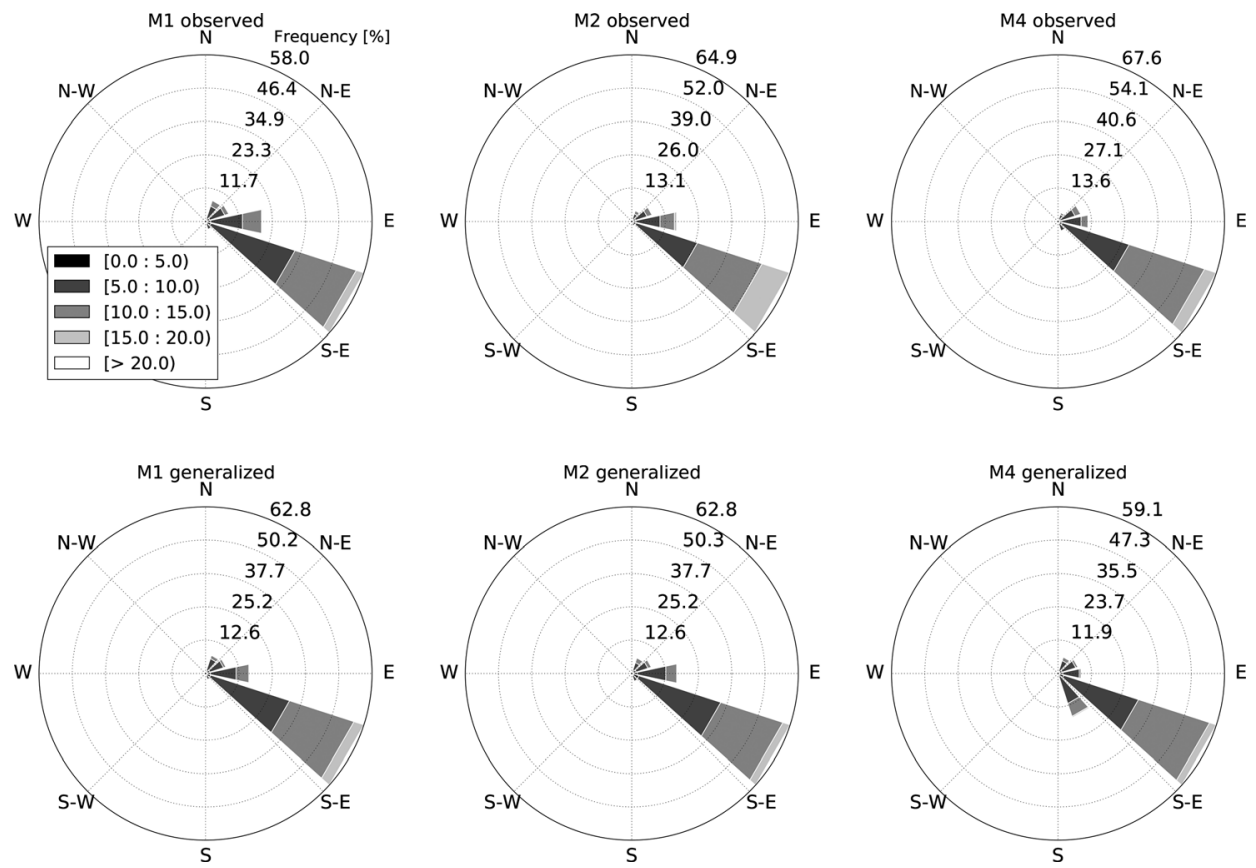

FIG. 9. Observed (top) and generalized (bottom) wind roses at $80 \mathrm{~m}$ for M1 (left), M2 (middle), and M4 (right).

and M1 are also illustrated. The generalization has clear problems when the winds are from $150^{\circ}$ and reach the position of M4.

\section{B. Self-predictions}

We analyze self-predictions (and so the vertical wind profiles) of the mean wind speed both sector-wise and omni-directionally. Predictions are made from $100 \mathrm{~m}$ to the other heights $(80$ and $120 \mathrm{~m}$ ). Figure 10 shows examples of the sector-wise self-predictions for different positions and sectors. Two observed profiles are plotted because of the different statistical methods to estimate the mean wind: TSA uses the simple mean average of all samples, whereas FDA (WAsP) uses a procedure based on Weibull distributions. For $150^{\circ}$, the vertical profiles at M6 are all very close, showing the goodness of the generalization at this position. However, for M4 and in a lesser degree for M1, the differences are high, reaching $\approx 3 \mathrm{~m} / \mathrm{s}$ in some cases. The models show again a good performance for generalizing winds from $120^{\circ}$, as illustrated by M4 and M5.

The contents in Fig. 11 are similar to those in Fig. 10 but show the omni-directional results for the seven met masts. These profiles are used to explore atmospheric stability issues. The vertical wind shear that results after using the FDA method is higher than that using the TSA method. This is because we assume neutral conditions for the TSA method and FDA (WAsP) considers a slightly stable atmosphere by default. Also, the resulting vertical wind shear when using CFD is higher than that using IBZ. CFD-TSA results are very close to the observations. It is important to note the rather large difference between the mean wind speeds of the observations using the FDA and TSA methods for masts M1 and M2. This is because the FDA in WAsP is performed in a way to match the power density and not the mean wind speed of the distributions, as the former is more important for wind energy. In some particular distributions, this results in a noticeable difference between the observed mean and the distribution-derived mean. The maximum difference between the sector-wise power densities of the methods is $2 \mathrm{~W} / \mathrm{m}^{2}$ only, for all masts.

Further, we correct the wind shear of the FDA profiles by adjusting the values of heat flux over land. The default value in WAsP is $-40 \mathrm{~W} / \mathrm{m}^{2}$ (Mortensen et al., 2013). This value can be adjusted for each mast position. We adjust the values of heat flux to match the vertical shear of 

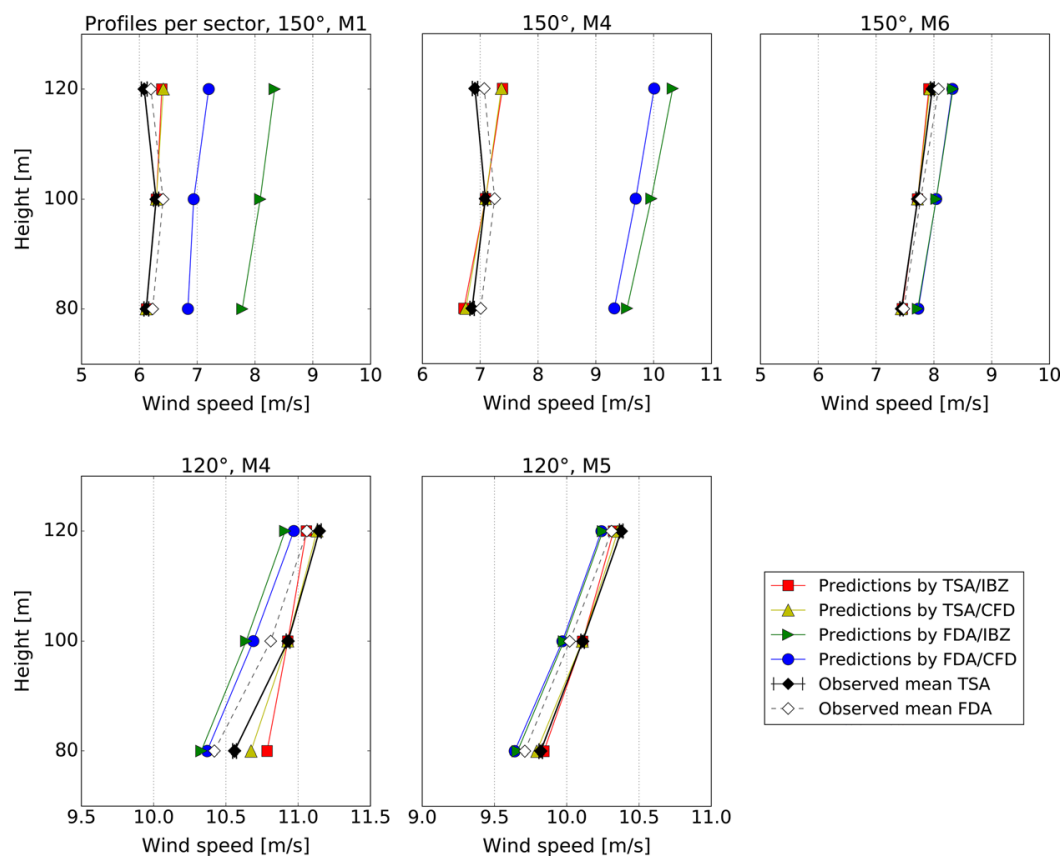

FIG. 10. Self-predictions by the different methods and the observed vertical wind profile. Top (bottom) figures illustrate M1, M4, and M6 (M4 and M5) for the direction $150^{\circ}\left(120^{\circ}\right)$. Error bars represent \pm standard errors of the observations.

the observed profile, for each mast. The corrected values are shown over the region's map in Fig. 12 for both the IBZ and CFD models. Since the CFD profiles show higher vertical wind shear than the IBZ profiles, the corrections are larger for CFD in all cases. It is also noticed that the larger corrections are for the positions farther from the escarpment, approaching values representative of those close to neutral conditions. Nonetheless, the effects of these corrections, in terms of wind speed, are not larger than $\approx 0.20 \mathrm{~m} / \mathrm{s}$ (not shown).
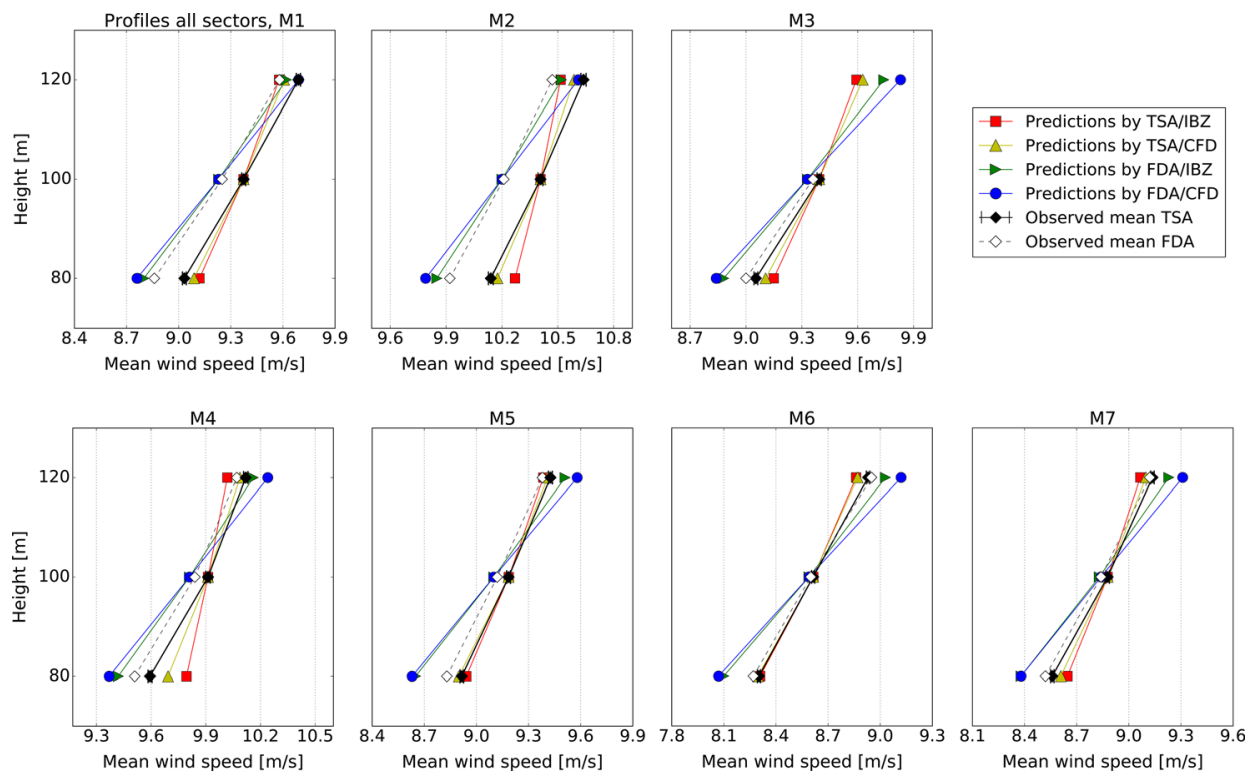

FIG. 11. The same as Fig. 10 but for all masts and showing the omni-directional results. 


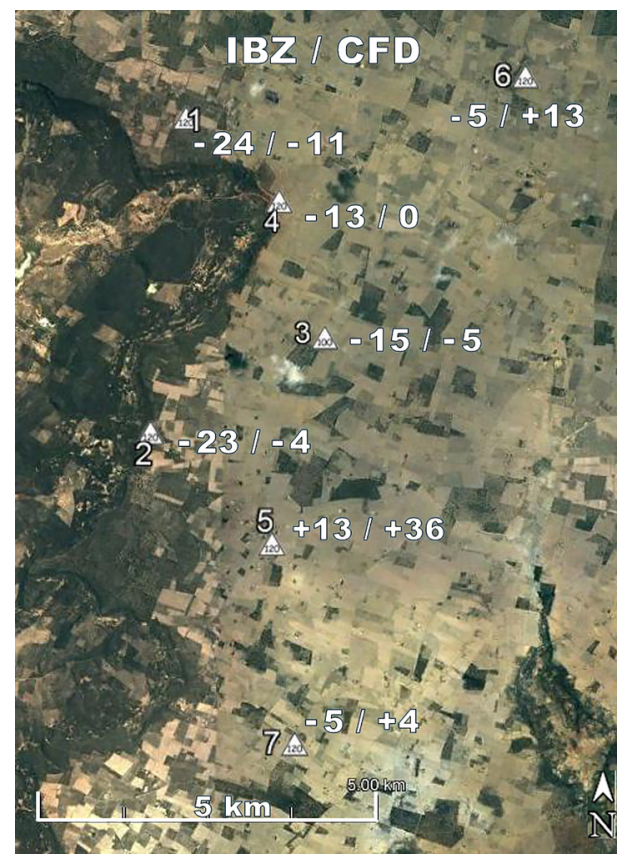

FIG. 12. A map of the region showing the corrected heat flux values in $\mathrm{W} / \mathrm{m}^{2}$ in WAsP IBZ/CFD.

\section{CONCLUSIONS}

Wind climate generalization methods were presented and used in a long series of 10-min mean winds from seven met masts deployed over a complex terrain region in Brazil. The methods showed high robustness for most masts and directions but some deficiencies at some mast positions for particular wind directions.

Both generalization methods performed well for the directional interval $30^{\circ}-120^{\circ}$, which includes the most frequent directions, and did not perform well for $150^{\circ}$, mainly. The critical sectors and sites were $150^{\circ}$ and $180^{\circ}$ and $\mathrm{M} 1, \mathrm{M} 2$, and M4 (all three near the borders of the plateau). The highest differences in terms of the generalized winds were found between these masts.

Vertical wind profile analyses showed that there was less vertical wind shear when TSA was applied compared to the results using FDA and the observed profiles. When compared to the default value in WAsP, the difference to the heat fluxes that need to be applied to the CFD solution is larger than that for the IBZ solution. The corrections were larger for positions farther from the escarpment. Nonetheless, the corrections resulted in differences in mean wind speed of less than $0.20 \mathrm{~m} / \mathrm{s}$.

Generally, using the CFD approach improved some results, but there was no clear advantage of using CFD over the IBZ model.

The above results might be due to the validity of the generalization method itself. First, it is here used in an equatorial region. Second, the distance between the masts is in the limits recommended for generalization and the wind climate between the positions might be strongly influenced by effects non-accounted for neither in the generalization nor in the microscale models, e.g., thermal effects or larger scale meteorological phenomena. Third, the complexity of the area is very high for some mast positions, in particular those near the plateau border, which are highly influenced by internal boundary layers induced by the escarpment. Although the generalization process is quite similar for both methods, their differences are mainly due to the statistical way that the procedure is performed in both.

Finally, the topographical effects estimated by the IBZ and CFD RANS approaches were rather similar. This is the main reason for the similarity in the results after generalization although the terrain is complex and the IBZ model is quite limited for such types of topographies. 


\section{ACKNOWLEDGMENTS}

The present work was performed with the support of $\mathrm{CNPq}$, Conselho Nacional de Desenvolvimento Cientifico e Tecnológico-Brazil, through the Science without Borders programme ("Ciências sem Fronteiras"). We also thank the Brazilian Government for the Scholarship No. 205150/2014-4 and the colleagues from DTU Wind Energy for the contributions. We are also very thankful to Casa dos Ventos Energias Renováveis S/A for allowing us access and publication of the wind data.

Albani, A. and Ibrahim, M. Z., Wind Eng. 38, 249 (2014).

Amarante, O. A. C., Brower, M., Zack, J., and A. L. Sá, Atlas do potencial eólico brasileiro (MME/Eletrobrás, Brasília, 2001), p. 45, in Portuguese.

Ayotte, K. W., J. Wind Eng. Ind. Aerodyn. 96, 1571 (2008).

Badger, J., Frank, H., Hahmann, A. N., and Giebel, G., J. Appl. Meteorol. Climatol. 53, 1901 (2014).

Banshwar, A., Sharma, N. K., Sood, Y. R., and Shrivastava, R., J. Renewable Sustainable Energy 9, 043306 (2017).

Basu, S., in Lecture Series: CFD for Atmospheric Flows and Wind Engineering (Von Kármán Institute for Fluid Dynamics, 2013).

Bechmann, A., Wind Model for Complex Terrain (DTU Wind Energy, Roskilde, Denmark, 2013).

Bechmann, A., "Data requirements for WAsP, CFD \& WRF," Technical Report No. Risø-E-0155(EN) (Technical University of Denmark, DTU Wind Energy, Roskilde, Denmark, 2017).

Bechmann, A., "Perdigão CFD grid study," Technical Report No. Risø-E-0120(EN) (Technical University of Denmark, DTU Wind Energy, Roskilde, Denmark, 2016).

Bechmann, A., Sørensen, N. N., Berg, J., Mann, J., and Réthoré, P.-E., Boundary-Layer Meteorol. 141, 245 (2011).

Bilal, M., Birkelund, Y., Homola, M., and Virk, M. S., Renewable Energy 99, 647 (2016).

Blocken, B., Hout, A., Dekker, J., and Weiler, O., J. Wind Eng. Ind. Aerodyn. 147, 43 (2015).

Bowen, A. J. and Mortensen, N. G., "WAsP prediction errors due to site orography," Technical Report No. Ris $\varnothing-$ R995(EN) (Technical University of Denmark, DTU Wind Energy, Roskilde, Denmark, 2004).

Brower, M. C., Wind Resource Assessment (John Wiley \& Sons Ltd., 2012), p. 280.

Cabezón, D., Iniesta, A., Ferrer, E., and Martí, I., in Proceedings of the European Wind Energy Association Conference \& Exhibition (Athens, 2006), p. 4

Castellani, F., Astolfi, D., Burlando, M., and Terzi, L., J. Wind Eng. Ind. Aerodyn. 147, 320 (2015).

Cavar, D., Réthoré, P.-E., Bechmann, A., Sørensen, N. N., Martinez, B., Zahle, F., Berg, J., and Kelly, M. C., Wind Energy Sci. Discuss. 1, 55 (2016).

de Jong, P., Dargaville, R., Silver, J., Utembe, S., Kiperstok, A., and Torres, E. A., Appl. Energy 195, 538 (2017).

Foken, T., Micrometeorology (Springer, 2008), p. 306.

Gasset, N., Landry, M., and Gagnon, Y., Energies 5, 4288 (2012).

Hahmann, A. N., Peña, A., and Carsten, J., "WRF mesoscale pre-run for the wind atlas of Mexico," Technical Report No.

Ris $\varnothing-E-0126$ (Ris $\varnothing$ National Laboratory, Roskilde, Denmark, 2016).

Jackson, P. S. and Hunt, J. C. R., Q. J. R. Meteorol. Soc. 101, 929 (1975).

Jothiprakasan, V. D., "Downscaling wind energy resource from mesocale to local scale by nesting and data assimilation with a CFD model," Ph.D. thesis (University of Paris-Est, 2014).

Lennard, C., Hahmann, A. N., Badger, J., Mortensen, N. G., and Argent, B., Energy Procedia 76, 128 (2015).

Michelsen, J. A., "Basis3D—A platform for development of multiblock PDE solvers," Technical Report No. AFM 92-05 (Risø National Laboratory, Roskilde, Denmark, 1992).

Mortensen, N., Rathmann, O., Nielsen, M., Kelly, M. C., Gryning, S.-E., Troen, I., Petersen, E. L., Na, A. P., Bingol, F., and Hansen, B. O., "WAsP 11 course notes," Technical Report No. DTU-Wind-I-0001(ed.4)(EN) (Risø National Laboratory, Roskilde, Denmark, 2013).

Murthy, K. S. R. and Rahi, O. P., Renewable Sustainable Energy Rev. 72, 1320 (2017).

Palma, J. M. L. M., Castro, F. A., Riberio, L. F., Rodrigues, A. H., and Pinto, A. P., J. Wind Eng. Ind. Aerodyn. 96, 2308 (2008).

Petersen, E. L., Mortensen, N. G., Landberg, L., Højstrup, J., and Frank, H. P., Wind Energy 1, 25 (1998a).

Petersen, E. L., Mortensen, N. G., Landberg, L., Højstrup, J., and Frank, H. P., Wind Energy 1, 55 (1998b)

Rasouli, A. and Hangan, H., ASME J. Sol. Energy Eng. 135, 041005 (2013).

Schlünzen, K. H., Grawe, D., Bohnenstengel, S. I., Schlüter, I., and Koppman, R., J. Wind Eng. Ind. Aerodyn. 99, 217 (2011)

Sempreviva, A. M., Larsen, S. E., Mortensen, N. G., and Troen, I., Boundary-Layer Meteorol. 50, 205 (1990).

Sørensen, N. N. "General purpose flow solver applied to flow over hills," Technical Report No. Ris $\varnothing-\mathrm{R}-827(\mathrm{EN})$ (Ris $\emptyset$ National Laboratory, Roskilde, Denmark, 1995).

Storm, B., Basu, S., and Nice, R. R. V., in AGU Fall Meeting Abstracts (2008), pp. A21E.

Troen, I. and Petersen, E. L., "European wind atlas," (Risø National Laboratory, Roskilde, Denmark, 1989), pp. 656, ISBN 87-550-1482-8.

Troen, I., Bechmann, A., Kelly, M. C., Sørensen, N. N., Réthoré, P.-E., Cavar, D., and Jørgensen, H. E., in Proceedings of the European Wind Energy Association Conference \& Exhibition (Barcelona, 2014).

Troen, I., in Proceedings of the 9th Symposium of Turbulence Diffusion (Roskilde, 1990).

Versteeg, H. K. E. and Malalasekera, W., An Introduction to Computational Fluid Dynamics: The Finite Volume Method (Longman Scientific \& Technical, 1995), p. 503.

Walmsley, J. L., Troen, I., Lalas, D. P., and Mason, P. J., Boundary-Layer Meteorol. 52, 259 (1990).

Yamada, T. and Koike, K., J. Wind Eng. Ind. Aerodyn. 9, 199 (2011).

Zajaczkowski, F. J., Haupt, S. E., and Schmehl, K. J., J. Wind Eng. Ind. Aerodyn. 99, 320 (2011).

Zhang, M. H., Wind Resource Assessment and Micrositing: Science and Engineering (John Wiley \& Sons Singapore Pte.

Ltd., 2015), p. 293. 